\title{
PENGUKURAN PENGARUH BELANJA DESA TERHADAP KINERJA PEMBANGUNAN DESA DENGAN MENGGUNAKAN GEOGRAPHICALLY WEIGHTED REGRESSION
}

\author{
Influence Measuring of Rural Expenditure Toward Rural \\ Development Performance by using Geograhically Weighted \\ Regression: A Case Study at Pandeglang District - Banten Province
}

\section{Eka Purna Yudha ${ }^{1}$, Bambang Juanda ${ }^{2}$, Lala M. Kolopaking ${ }^{3}$, and Rilus A. Kinseng ${ }^{3}$}

\begin{abstract}
Abstrak: Pada tahun 2014, Pemerintah mengeluarkan Undang-Undang No 6/2014 tentang Desa dengan maksud merekonstruksi pengaturan urusan keuangan keuangan desa dan aset desa untuk mempercepat akselerasi pembangunan perdesaan yang inklusif dan berkelanjutan. Tujuan penelitian adalah menganalisis pengaruh pengelolaan keuangan desa tersebut terhadap kinerja pembangunan perdesaan. Penelitian ini dilakukan pada 326 Desa di Kabupaten Pandeglang. Alat analisis dari penelitian menggunakan pemodelan Geographically Weighted Regression (GWR) akan melihat bagaimana pengaruh belanja desa yang tercantum alam Anggaran Pendapatan dan Belanja Desa (APBDes). Belanja pelaksanaan pembangunan (infrastruktur) desa berpengaruh paling besar terhadap kinerja pembangunan desa dengan nilai elastisitas sebesar 0,637. Pengaruh belanja desa pada model GWR sangat dipengaruhi oleh kondisi geografis, demografis, dan juga sosial ekonomi masyarakat desa, sehingga memiliki hasil yang bervariatif pada masing-masing desa.
\end{abstract}

Keyword in Bahasa: APBDes, kinerja, pembangunan desa

\begin{abstract}
In 2014, the Government enacted Law No. 6/2014 on Villages with a view to reconstructing village financial and asset management arrangements to accelerate the inclusive and sustainable development of rural areas. The purpose of this study is to analyze the influence of village financial management on the performance of rural development. The study was conducted on 326 Villages in Pandeglang District. The analytical tool of the study using Geographically Weighted Regression (GWR) modeling will look at how the village expenditure is included in the Village Revenue and Expenditure Budget (APBDes). Expenditure of development (infrastructure) of the village has the greatest impact on the performance of village development with the value of elasticity of 0.637 . The influence of village expenditure on the GWR model is strongly influenced by the geographical, demographic, and socio-economic conditions of rural communities, resulting in varying outcomes in each village.
\end{abstract}

Keywords: APBDes, kinerja, pembangunan desa

1 Program Studi Ilmu Perencanaan Pembangunan Wilayah dan Perdesaan, Pascasarjana IPB

2 Departemen Ilmu Ekonomi, Fak. Ekonomi dan Manajemen, IPB

3 Departemen Sains Komunikasi dan Pengembangan Masyarakat, Fak. Ekologi Manusia, IPB

Korespondensi:eka.purna.yudha@gmail.com 


\section{PENDAHULUAN}

Pelaksanaan pembangunan selama ini masih menimbulkan kesenjangan antara perkotaan dan perdesaan. Hal ini terjadi karena adanya kebijakan yang kurang berpihak pada pembangunan di daerah perdesaan sehingga timbul berbagai permasalahan ketidak berimbangan kesejahteraan antar wilayah (Pranoto, 2005). Isu ketimpangan pembangunan ini juga diperkuat oleh Pribadi (2005), menjelaskan bahwa dalam konteks spasial, proses pembangunan yang telah dilaksankan selama ini telah menimbukkan berbagai permasalahan yang berkaitan dengan tingkat kesejahteraan wilayah yang tidak berimbang. Berkembangnya kota sebagai pusat-pusat pertumbuhan ternyata tidak memberikan efek penetesan ke bawah (trickledown effect), tetapi justru menimbulkan efek pengurasan sumberdaya dari wilayah di sekitarnya (backwash effect).

Implementasi dari dana pembangunan perdesaan melalui undang-undang desa memberikan peluang baru yang bisa meningkatkan lapangan kerja melalui programprogram pemberdayaan perdesaan yang bersifat padat karya. Namun perlu dilihat lebih mendalam, sejauh mana pengaruh implementasi dana desa ini terhadap variabel-variabel pembangunan perdesaan. Pemberian anggaran untuk kawasan perdesaan ini oleh beberapa pengamat ekonomi akan memberikan berbagai dampak turunan baik yang mampu mendorong berjalannya sektor riil dan terbukanya lapangan pekerjaan di perdesaan. Beberapa hasil penelitian menunjukkan peran yang positif dari modal pemerintah terhadap pertumbuhan ekonomi (Aschauer 1989).

Munculnya Undang-Undang No 6/2014 tentang Desa memberikan sebuah harapan baru terhadap desa, harapannya peraturan perundangan ini mampu mendorong prakarsa, gerakan, dan partisipasi masyarakat Desa untuk pengembangan potensi dan Aset Desa guna kesejahteraan bersama; membentuk Pemerintahan Desa yang profesional, efisien dan efektif, terbuka, serta bertanggung jawab; memajukan perekonomian masyarakat Desa serta mengatasi kesenjangan pembangunan nasional; dan memperkuat masyarakat Desa sebagai subjek pembangunan.

Dalam menjalankan pemerintahan desa, maka Undang-undang 6/2014 tentang desa mengatur urusan keuangan desa dan aset desa. Pasal 71 ayat 2 diatur hak dan kewajiban yang terdiri dari pendapatan, belanja, pembiayaan, dan pengelolaan keuangan desa. Sejak tahun 1980 strategi pembangunan yang berorientasi bottom-up telah diperkenalkan, sehingga memungkinkan masyarakat setempat untuk membuat keputusan sendiri mengenai kebijakan ekonomi.

Vennesland (2003), menjelaskan bahwa skema bantuan pembangunan perdesaan (RDSS) di Norwegia ditemukan 13 dari 18 (72\%) daerah di Noerwegia menunjukkan hasil output yang rendah pada produktivitas tenaga kerja dari tingkat tertentu terhadap anggaran RDDS secara teknis, sehingga perlu dilakukannya realokasi anggaran RDDS yang ditujukan untuk tujuan maksimisasi output dari pekerjaan yang sudah ada di perdesaan Norwegia. Oates (1999) menyatakan desentralisasi dilaksanakan untuk meningkatkan kemandirian daerah dan efisiensi anggaran. Lebih lanjut Bjornestad (2009) menyatakan pemberian keleluasaan kepada pemerintah daerah dalam mengambil kebijakan terhadap program dan pengelolaan anggaran juga akan meningkatkan efektivitas penyediaan layanan umum kepada masyarakat.

Howe et al (1997) mengatakan rencana di tingkat desa diperlukan untuk menjaga kualitas lingkungan dan budaya di desa tetap seimbang, seiring dengan peningkatan permintaan akan pembangunan perumahan dan kegiatan ekonomi wilayah yang menjadi semakin kompleks di wilayah desa. Desa secara administratif dalam Undang-Undang Nomor 6 tahun 2014 tentang Desa memiliki kewenangan untuk mengatur dan mengurus urusan pemerintahannya sendiri. Kegiatan dalam kegiatan musyawarah desa tersebut 
bukan hanya sosialisasi satu arah, tetapi masyarakat juga diberikan kesempatan untuk berbicara maupun mengeluarkan pendapat mereka (Moore, 2005).

Peningkatan kemandirian desa ini sebetulnya yang akan menjadi tujuan akhir dari pemberlakukan undang-undang desa. Dana desa yang digulirkan harus memacu kemadirian, bukan memunculkan ketergantungan. Penelitian di Iran menunjukkan bahwa subsidi tunai menyebabkan kesejahteraan pengurangan dan produktivitas selama periode pelaksanaan subsidi yang ditargetkan dalam masyarakat Iran (Shahmoradi et al, 2011; Parvayi, 2011; Ranjbar et al, 2014.). Oleh karena itu, dana desa yang sudah berjalan hampir dua tahun ini harus dioptimalkan secara bijak dan sesuai dengan kebutuhan dengan mempertimbangkan keberlanjutan sumberdaya lokal dan juga perkembangan perekonomian desa. Penelitian ini mencoba mengkaji implementasi penggunaan dana dan pengaruhnya terhadap kinerja pembangunan perdesaan berdasarkan UU No 6 tahun 2014.

\section{METODE PENELITIAN}

Faktor-faktor belanja desa yang diduga berpengaruh terhadap kinerja pembangunan perdesaan diuji signifikansi hubungannya dalam bentuk pemodelan (Juanda et al 2013). Pemodelan faktor-faktor belanja desa yang mempengaruhi kinerja pembangunan desa dilakukan melalui dua pendekatan unit analisis yaitu analisis OLS dan Geographically Weighted Regression (GWR). Model OLS akan melihat secara umum model pengaruh belanja desa terhadap kinerja pembangunan Desa. Model GRW akan melihat secara spesifik pengaruh belanja desa tersebut terhadap kinerja pembangunan pada tiap unit desa (Fischer et al 1996).

Pemodelan ekonometrika OLS dapat dikonstruksi pada model di bawah ini.

$\mathrm{IDM}_{\mathrm{i}}=\beta_{0}+\beta_{1} \mathrm{BPM}_{\mathrm{i}}+\beta_{2} \mathrm{BPD}_{\mathrm{i}}+\beta_{3} \mathrm{BDM}_{\mathrm{i}}+\beta_{4} \mathrm{BDMY}_{\mathrm{i}}+\beta_{5}$ Dummy $+\mathrm{e}_{\mathrm{i}}$

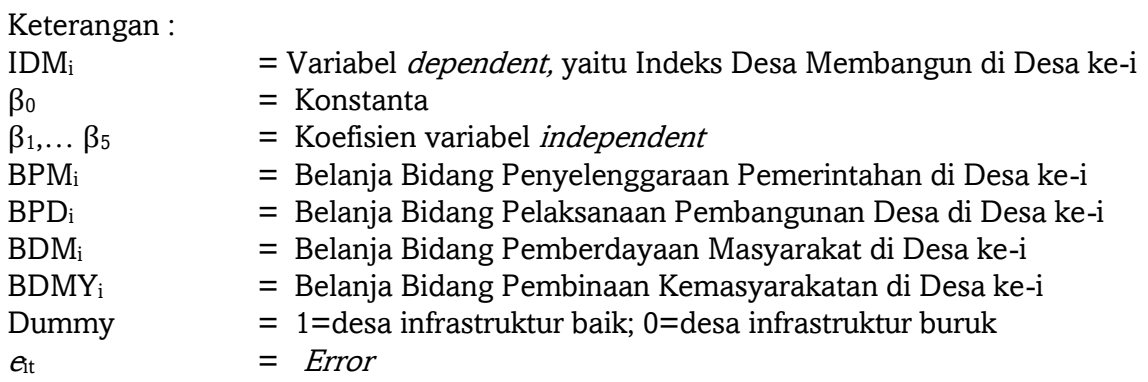

Pemodelan GWR dapat dikonstruksi pada model di bawah ini.

$$
\begin{gathered}
I D M_{i}=\beta_{0}\left(u_{i}, v_{i}\right)+\beta_{1}\left(u_{i}, v_{i}\right) B P M_{i}+\beta_{2}\left(u_{i}, v_{i}\right) B P D_{i}+\beta_{3}\left(u_{i}, v_{i}\right) B D M_{i} \\
+\beta_{4}\left(u_{i}, v_{i}\right) B D M Y_{i}++\varepsilon_{i}
\end{gathered}
$$

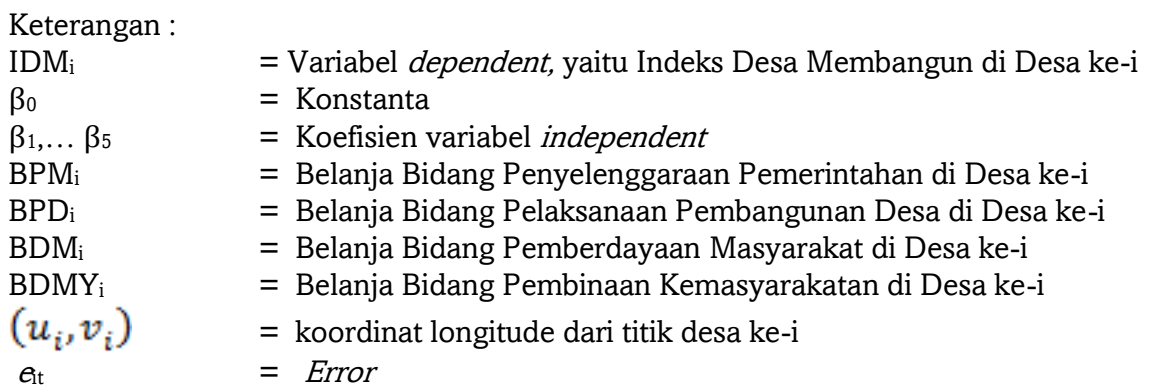


Dalam menganalisis hasil dari pemodelan ekonometrika spasial, akan dilakukan tekni overlay dengan berbagai kondisi indeks desa membangun, pola penggunaan lahan, pola sebaran potensi unggulan, pola sebaran infrastruktur, pola sebaran topografi kawasan, dan pola sebaran sosial, ekonomi dan budaya masyarakat (Fotheringham et al. 2002).

Pembangunan perdesaan diidentifkasi secara deskriptif faktor karakteristik potensi desa, faktor internal kelembagaan desa, dan faktor eksternal (Valentin 2001). Rekomendasi kebijakan pengembangan dan percepatan pembangunan desa dianalisis secara deskriptif. Informasi yang digunakan untuk merumuskan kebijakan penanganan pembinaan desa berasal dari hasil analisis faktor penyebab dan identifikasi faktor-faktor belanja desa yang berpengaruh terhadap kinerja pembangunan desa (Bjornestad 2009).

\section{PEMBAHASAN}

Hasil perbandingan antara model OLS dan GWR, diperoleh bahwa dengan unit analisis desa pada model GWR lebih tinggi tingkat kebaikan modelnya. Dengan unit analisis desa, penelitian mampu menggambarkan batas antar desa yang lebih kongkret dibandingkan dengan batas antar kabupaten pada model secara umum. Karakteristik dan faktor-faktor belanja desa yang mempengaruhi tingkat kinerja pembangunan perdesaan dapat terlihat secara lebih detail di setiap desa.

Tabel 1 Hasil Estimasi Parameter Regresi OLS dan GWR Pengaruh Belanja Desa Terhadap Kinerja Pembangunan Perdesaan di desa pada Kabupaten Pandeglang

\begin{tabular}{|c|c|c|c|c|c|}
\hline \multirow{2}{*}{ Variabel } & \multirow{2}{*}{$\begin{array}{l}\text { OLS } \\
\text { Model }\end{array}$} & \multirow{2}{*}{$\begin{array}{l}\text { Elastisitas } \\
\text { OLS Model }\end{array}$} & \multicolumn{3}{|c|}{ GWR Model } \\
\hline & & & Min. & Rata-Rata & Max \\
\hline Intercept & $91,6^{\star}$ & - & $-7,6498074$ & 0,0262206 & 6,1365126 \\
\hline Belanja Bidang & & & & & \\
\hline $\begin{array}{l}\text { Penyelenggaraan } \\
\text { Pemerintahan Desa }\left(\mathrm{X}_{1}\right)\end{array}$ & $83,2^{*}$ & 0,107 & $-0,3707710$ & 0,0325596 & 0,5388930 \\
\hline Belanja Bidang & & & & & \\
\hline $\begin{array}{l}\text { Pelaksanaan } \\
\text { Pembangunan }\end{array}$ & $93,6^{\star}$ & 0,637 & $-0,027873$ & 0,091021 & 0,0171458 \\
\hline Infrastruktur Desa $\left(\mathrm{X}_{2}\right)$ & & & & & \\
\hline Belanja Bidang & & & & & \\
\hline Pemberdayaan & $93,7^{*}$ & 0,019 & $-0,0281621$ & 0,0012399 & 0,0931275 \\
\hline Masyarakat $\left(\mathrm{X}_{3}\right)$ & & & & & \\
\hline Belanja Bidang & & & & & \\
\hline Pembinaan & $625^{*}$ & 0,084 & $-0,0491633$ & 0,0032393 & 0,0745166 \\
\hline Kemasyarakatan $\left(\mathrm{X}_{4}\right)$ & & & & & \\
\hline Dummy & $0,065^{\star}$ & - & & & \\
\hline $\mathrm{N}$ & 325 & & & & 325 \\
\hline $\mathrm{R}^{2}$ & 32,01 & & & & 99,6 \\
\hline AIC & 290,71 & & & & 81,212 \\
\hline SSE & 441,2 & & & & 357,6 \\
\hline Asumsi terpenuhi & $1,2,3,4$ & & & & \\
\hline P Value uji Leung & 0,000 & & & & 0,00033 \\
\hline
\end{tabular}

Keterangan:

Signifikansi: *) signifikan 5\%, **) Signifikan $10 \%$

Asumsi residual: 1) distribusi normal, 2) homogen, 3) independen, 4) tidak multikolinieritas

Berdasarkan pemodelan OLS dengan dummy berupa desa dengan infrastruktur baik dan desa dengan infrastruktur buruk, dapat terlihat bahwa belanja pelaksanaan pembangunan infrastruktur desa berpengaruh paling besar terhadap kinerja pembangunan desa. Pengaruh ini berupa nilai elastisitas sebesar 0,637. Kemudian diikuti oleh belanja bidang penyelenggaraan pemerintahan desa dengan nilai elastisitas sebesar 0,107. Selanjutnya belanja bidang pembinaan kemasyarakatan dengan nilai elastisitas sebesar 0,084, dan terakhir adalah belanja bidang pemberdayaan masyarakat dengan nilai elastisitas sebesar 0,019. Ayoola (2001) juga berpendapat bahwa, pembangunan 
infrastruktur perdesaan dianggap sebagai kebutuhan utama masyarakat pedesaan untuk mewujudkan potensi ekonomi. Ekong (2003) juga melihat infrastruktur pedesaan sebagai dasar modal fisik, sosial dan kelembagaan mendasar yang dapat meningkatkan kegiatan produksi, pendistribusian dan konsumsi penduduk pedesaan, dan pada akhirnya kualitas hidupnya.

Pembangunan desa bertujuan untuk meningkatkan kualitas hidup manusia serta penanggulangan kemiskinan, melalui penyediaan pemenuhan kebutuhan dasar, pembangunan sarana dan prasarana, pengembangan potensi ekonomi lokal, serta pemanfaatan sumber daya alam dan lingkungan secara berkelanjutan. Pembangunan desa harus mempertimbangkan keragaman, partisipasi, otonomi adat, demokratisasi, dan pemberdayaan. Namun dalam pelaksanaannya masih terdapat hambatan utama berupa keterlibatan masyarakat, terutama dalam aspek aspirasi masyarakat terhadap pembangunan desa (Warsono H, Ruksamin 2014)

Pemerintahan Desa adalah penyelenggaraan urusan pemerintahan dan kepentingan masyarakat setempat dalam sistem pemerintahan NKRI. Belanja bidang penyelenggaraan pemerintah desa lebih berfokus pada kegiatan-kegiatan yang bersifat pelayanan kantor dan administrasi kependudukan. Pelayanan administrasi kependudukan dan kewilayahan ini meliputi penetapan batas desa, pelayanan administrasi kependudukan, pengelolaan data dan informasi desa, perencanaan dan evaluasi kegiatan pembangunan desa, kerjasama desa, dan pembangunan sarana prasarana kantor desa. Kinerja pemerintah desa terutama aparatnya memegang peranan yang sangat besar dalam menentukan keberhasilan sebuah progam pembangunan desa (Gieske, van Buuren dan Bekkers 2016).

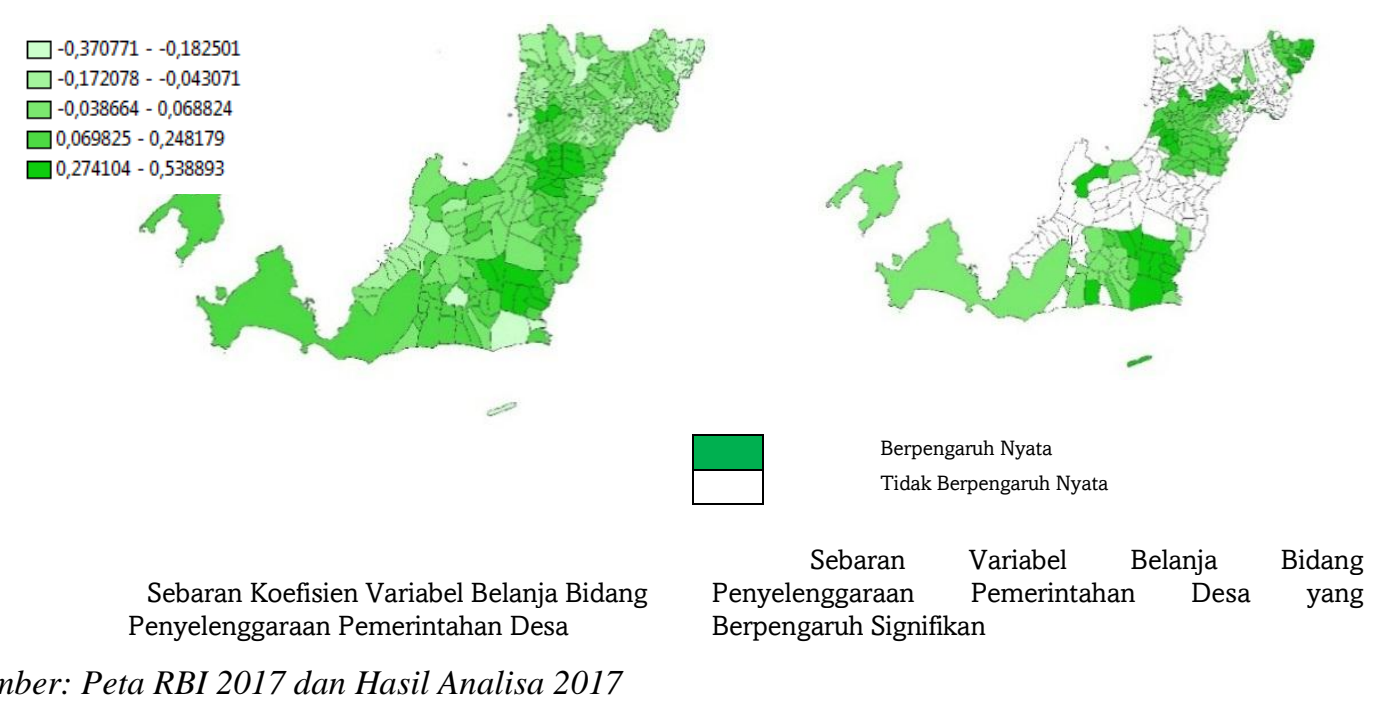

Gambar 1 Signifikansi Hubungan Pengaruh Belanja Bidang Penyelenggaraan Pemerintahan Desa terhadap Kinerja Pembangunan Desa (IDM)

Dalam pemodelan GWR pada Gambar 1, dapat terlihat bahwa sebaran belanja desa bidang penyelenggaraan pemerintahan desa yang berpengaruh meningkatkan IDM banyak ditemui pada desa-desa yang berada pada wilayah selatan dan wilayah tengah. Selain itu juga desa-desa yang cenderung ke arah selatan yang merupakan lokasi-lokasi desa tertinggal dan sangat tertinggal. Kegiatan-kegiatan perencanaan pembangunan dan pelayanan desa sampai saat ini cukup efektif dan efisien sesuai dengan kebutuhan masyarakat dan mampu memenuhi indikator-indikator pendukung IDM. 
Peranan pemerintah desa sebagai pelopor pembangunan desa sudah mampu menangani masalah pembangunan yang ada di desa meliputi perencanaan program pembangunan desa (Mischen dan Sinclair, 2017). Faktor kepemimpinan akan mendorong mendorong budaya kolaboratif yang memungkinkan pengembangan keterampilan dan pengetahuan yang diperlukan untuk menerapkan reformasi administratif. Sistem pelayanan yang maksimal dapat teraplikasikan dengan baik apabila didukung oleh aparat desa sebagai pelaksana yang mampu memahami tugas-tugasnya (Pade 2015).

Dalam merancang program-program pembangunan desa, pekerjaan rumah terbesar pemerintah desa adalah meningkatkan tingkat partisipasi masyarakat. Penyediaan Dana Alokasi Desa didasarkan pada otonomi desa ditujukan agar desa bisa tumbuh dan berkembang mengikuti pertumbuhan yang berasal dari desa itu sendiri. Pembangunan desa harus mempertimbangkan keragaman, partisipasi, otonomi adat, demokratisasi, dan pemberdayaan. Namun dalam pelaksanaannya masih terdapat hambatan utama berupa keterlibatan masyarakat, terutama dalam aspek aspirasi masyarakat terhadap pembangunan desa (Warsono H, Ruksamin 2014).

Strategi pelaksanaan partisipasi dicapai dengan cara melibatkan masyarakat dalam sharing imformasi, merumuskan tujuan, menseting kebijakan, mengalokasikan sumbersumber pendanaan, mengoperasikan program, serta mendistribusikan manfaat yang diperoleh, dengan kata lain, melibatkan masyarakat sejak tahap perencanaan hingga implementasi dan pemerataan hasil-hasilnya (Kagoya et al. 2015). Hal ini sejalan dengan hasil penelitian Lestari (2015) yang menyatakan bahwa partisipasi dari masyarakat dan lembaga lainnya juga sangat diperlukan karena keterbukaan dan transparansi di dalam pelaksanaan pembangunan dapat memperlancar jalannya pembangunan desa.

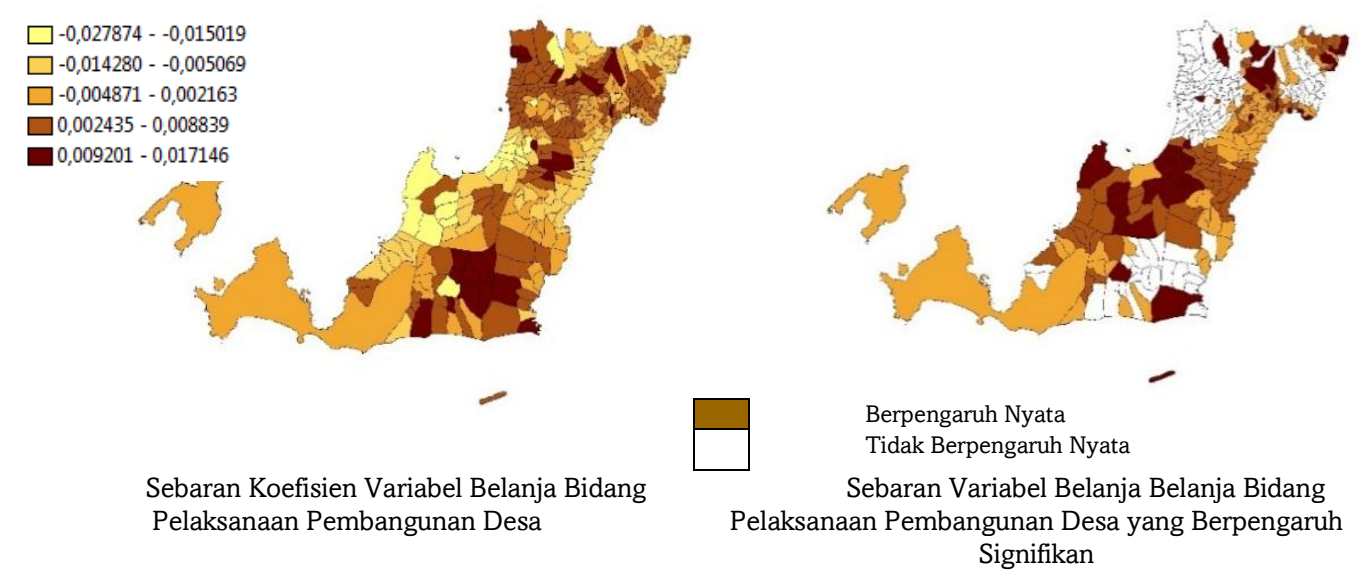

Sumber: Peta RBI 2017 dan Hasil Analisa 2017

Gambar 2 Signifikansi Hubungan Pengaruh Belanja Bidang Pelaksanaan Pembangunan Desa terhadap Kinerja Pembangunan Desa

Belanja desa pada Gambar 2 untuk kegiatan pelaksanaan pembangunan infrastruktur desa yang secara signifikan meningkatkan IDM ini banyak terdapat di desa yang memiliki topografi landai. Peningkatan kualitas kinerja pembangunan desa tersebut mengindikasikan bahwa kegiatan-kegiatan pembangunan sesuai dengan kebutuhan masyarakat, mampu menyelesaikan permasalahan infrastruktur dasar di desa, dan tepat sasaran. Apabila dilihat secara geografis, desa-desa yang nilai belanja BPD memiliki pengaruh negatif memiliki tingkat kesulitan geografis yang lebih sulit dibandingkan dengan desa-desa lainnya. Selain itu, desa-desa yang berpengaruh menurunkan IDM juga sebagian 
besar merupakan desa yang didominasi oleh kegiatan pertanian lahan kering dan masih banyaknya kawasan hutan di dalam area desa.

Dalam studinya di Tamil Nadu, India investasi pada infrastruktur pedesaan seperti jaringan irigasi, pasar pedesaan dan jalan menyebabkan peningkatan produktivitas (total factor productivity) pada sektor pertanian. Hasil penelitian secara tegas menunjukkan bahwa pembangunan infrastruktur adalah determinan penting total factor productivity dan efisiensi produksi pertanian (Ashok dan Balasubramanian, 2006).

Dari berbagai pembangunan infrastruktur yang telah dibangun, ternyata infrastruktur yang paling berpengaruh terhadap perkembangan desa adalah infrastruktur jalan. Ahmed dan Hossein (1990) menyatakan bahwa Pembangunan infrastruktur mempengaruhi biaya transportasi dan margin yang didapatkan produsen (pedagang). Karena dengan semakin tipisnya biaya transportasi, maka semakin tinggi juga margin per unit yang harus dipertahankan oleh pedagang dalam bisnisnya di perdesaan. Pembangunan infrastruktur menghasilkan peluang bagi lapangan kerja lainnya. Secara tidak langsung, pembangunan infrastruktur mempengaruhi lapangan kerja melalui difusi teknologi modern intensif tenaga kerja. Pengaruh pembangunan jalan baru cukup kuat seperti yang ditunjukkan dalam studi yang dilakukan World Bank di India, Pakistan and Brazil (Creightney, 1993 and Lall dan Shalizi 2001).

Perbaikan infrastruktur transportasi berpengaruh pada produksi dan konsumsi rumah tangga melalui penurunan biaya transportasi dan/atau waktu perjalanan sehingga meningkatkan aksesibilitas pasar dan input. Pada gilirannya ini akan memberikan pengaruh redistribusi pada kelompok ekonomi dan antar wilayahPerbaikan infrastruktur transportasi berimplikasi ekonomi regional dapat menggunakan faktor produksi privat secara lebih produktif. Meningkatnya kualitas infrastruktur transportasi berarti lebih rendahnya kebutuhan modal dan tenaga kerja (Rietveld dan Nijkamp, 1992).

Fan dan Kang (2004) mengemukakan bahwa jalan dengan kualitas rendah memiliki rasio biaya-manfaat terhadap GDP nasional yang lebih besar dibandingkan dengan jalan kualitas bagus. Malmberg et al. (1997) menemukan bahwa infrastruktur jalan memiliki dampak pada pertumbuhan ekonomi baik di sektor pertanian maupun non-pertanian, dan menciptakan kesempatan ekonomi bagi penduduk desa secara keseluruhan. Infrastruktur jalan menyebabkan produksi hasil pertanian bernilai tinggi, dan meningkatkan kesempatan kerja sektor non-pertanian. Kwon (2001) meneliti peran infrastruktur jalan desa dalam pengurangan kemiskinan di Indonesia. Menurutnya penduduk miskin pada umumnya terkonsentrasi di pedesaan dan cenderung terisolasi dengan daerah lainnya. Transportasi pedesaan yang lebih baik menyebabkan petani mampu meningkatkan kegiatannya dengan biaya input yang lebih rendah. Malmberg et al. (1997) menemukan bahwa infrastruktur jalan memiliki dampak pada pertumbuhan ekonomi baik di sektor pertanian maupun bukan, dan menciptakan kesempatan ekonomi bagi penduduk desa secara keseluruhan, termasuk yang miskin. Infrastruktur jalan menyebabkan produksi hasil pertanian bernilai tinggi, dan meningkatkan kesempatan kerja bukan pertanian.

Sebaran belanja desa pada Gambar 3, untuk bidang pemberdayaan masyarakat yang berpengaruh meningkatkan IDM banyak ditemui pada desa-desa yang berada pada wilayah yang memiliki topografi landai dan wilayah pesisir Pandeglang dan sebagian besar berada pada desa yang telah ditepatkan sebagai kawasan strategis kabupaten. Desa-desa yang berpengaruh menurunkan IDM juga belum memiliki komoditas unggulan desa yang bisa menjadi penggerak perekonomian desa, sehingga program-program pemberdayaan masyarakat masih harus ditingkatkan dan perlu inovasi-inovasi terbaru agar bisa meningkatkan nilai jual yang lebih tinggi.

Desa-desa di Kabupaten Pendeglang memiliki komoditas unggulan yang sudah dikembangkan dan memiliki pola ekspansi pasar cukup baik di dalam maupun di luar Kabupaten Pandeglang. Kegiatan pemberdayaan masyarakat pada desa yang sudah ada ini 
harus terus dikembangkan agar dapat menjadi trigger perekonomian masyarakat desa. Pemberdayaan masyarakat dapat dimulai dengan pelayanan aparatur desa yang lebih responsif dan lebih inklusif, peningkatan akses pasar yang lebih adil, penguatan masyarakat desa dan organisasi masyarakat desa, dan peningkatan aset kepemilikan dan kebebasan dalam berpartisipasi (Narayan 2002).

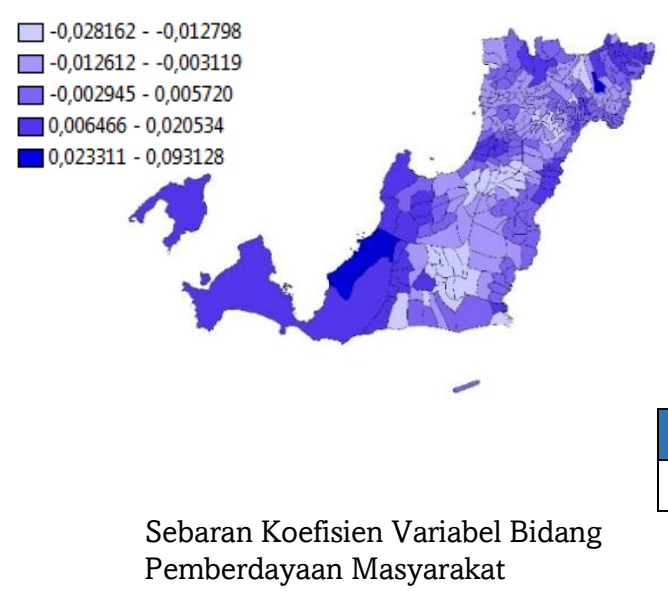

Pemberdayaan Masyarakat

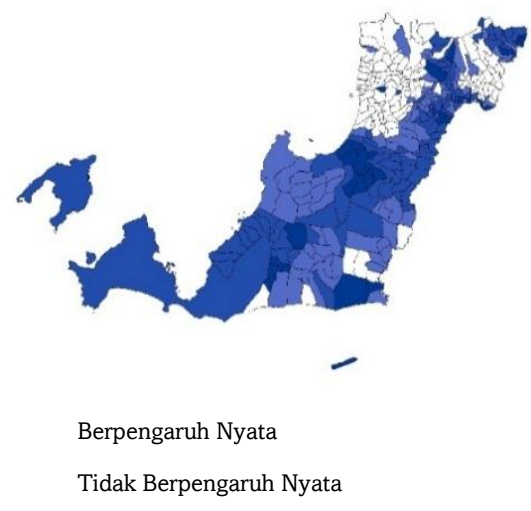

Sebaran Variabel Belanja Bidang Pemberdayaan Masyarakat yang Berpengaruh Signifikan

Sumber: Peta RBI 2017 dan Hasil Analisa 2017

Gambar 3 Signifikansi Hubungan Pengaruh Belanja Bidang Pemberdayaan Masyarakat terhadap Kinerja Pembangunan Desa

Pemberdayaan masyarakat merupakan pendekatan yang berguna untuk semua negara. Pembedayaan masyarakat desa dan berfokus pada pembangunan pertanian dapat membantu pembangunan pedesaan dan memastikan masyarakat desa dapat memenuhi kebutuhan dasar mereka (Rahimi 2015). Keberhasilan pemberdayaan masyarakat tergantung pada dorongan masyarakat untuk berpartisipasi aktif dalam perancangan dan implementasi program pembangunan pertanian. Selain itu pemerintah desa juga didorong untuk meningkatkan kegiatan investasi dan sektor swasta di sektor pertanian, menciptakan suasana saling percaya antara masyarakat dan pemerintah desa, menciptakan sistem kredit yang efektif, pengembangan pasar untuk produk pertanian, dan meningkatkan akses petani terhadap bibit, pupuk, dan obat untuk ternak.

Untuk memulai proses pembedayaan, diperlukan komitmen anggota masyarakat terhadap pendekatan pembangunan di masa depan (Frank dan Smith 1999). Pemberdayaan masyarakat dan kaitannya dengan pemangku kepentingan dalam pengelolaan potensi sumberdaya desa merupakan tantangan karena mempengaruhi pola hubungan kekuatan pemimpin di desa yang lebih mapan (Reimer 2006). Oleh karena itu, organisasi pemerintahan desa harus menunjukkan nilai mereka sebagai mitra sah dalam pengelolaan potensi lokal dan mengamankan dana yang mengembangkan mekanisme pemberdayaan baru dan menopang mekanisme baru untuk meningkatkan kapasitas masyarakat dalam perencanaan dan pelaksanaan pembangunan desa (Strzelecka 2015).

Dengan adanya peningkatan kapasitas maka akan meningkatkan kolektifitas masyarakat dalam bentuk kelembagaan dan hubungan modal sosial untuk menghadapi tantangan dan menciptakan hasil yang bermanfaat bagi masyarakat (Beckley et al., 2002). Modal sosial masyarakat merupakan keterampilan, pendidikan, pengalaman kerja dan kualitas hidup sehat masyasrakat. Modal manusia juga dapat berupa kepemimpinan, 
kewirausahaan, keterampilan memecahkan masalah dan pengetahuan lokal (Flora 1994). Hal ini dapat diperoleh melalui pendidikan formal atau informal melalui pengalaman kerja dan interaksi sosial dengan keluarga dan teman (Beckley et al., 2002).

Belanja desa pada Gambar 4 bidang pembinan kemasyarakatan ini relatif memiliki pengaruh yang signifikan hampir pada seluruh tipologi desa, mulai dari desa maju, desa berkembang, desa tertinggal, dan desa sangat tertinggal. Kegiatan-kegiatan pembinaan masyarakat secara signifikan mampu meningkatkan IDM pada wilayah-wilayah yang memiliki basis pendidikan keagamaan atau pesantren yang masih kuat, dimana notabene banyak tersebar di wilayah tengah Kabupaten Pandeglang. Oleh karena itu, kegiatankegiatan pembinaan kemasyarakat yang banyak bersinggungan dengan kegiataan keagamaan yang dipadu dengan pembinaan organisasi sosial kemasyarakat sangat efektif meningkatkan kinerja pembangunan desa dalam hal ini adalah IDM. Kondisi kontradiktif lainnya yang perlu dicermati adalah desa-yang berada pada wilayah yang tidak memiliki basis pendidikan keagamaan yang kuat seperti pesantren justru tidak mampu meningkatkan IDM.

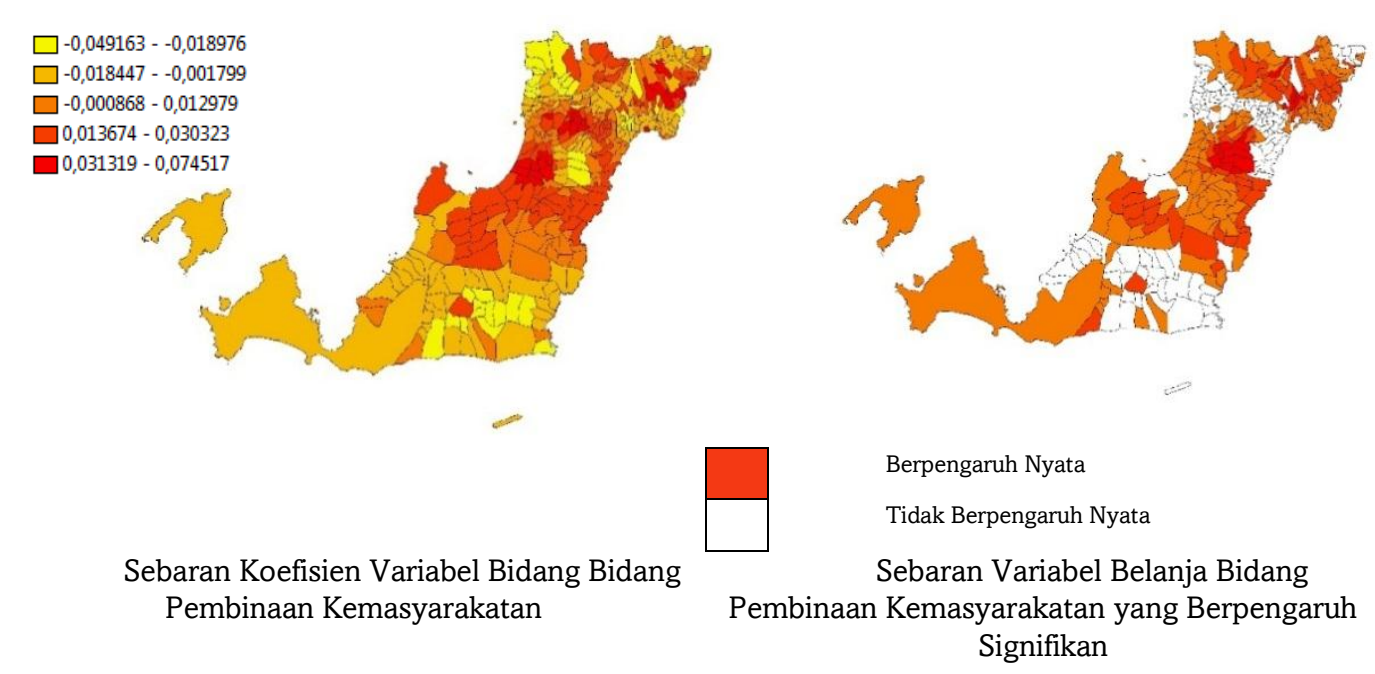

Sumber: Peta RBI 2017 dan Hasil Analisa 2017

Gambar 4 Signifikansi Hubungan Pengaruh Belanja Bidang Pembinaan Kemasyarakatan terhadap Kinerja Pembangunan Desa

Pembinaan kemasyarakatan merupakan salah satu program pemerintah dalam meningkatkan serta mengelola lembaga dan sumber daya manusia agar lebih baik dan bekerja sesuai dengan harapan. Pembinaan kemasyarakat dapat dilakukan dengan berbagai cara baik melalui pelatihan, rapat, lomba, peringatan hari besar nasional maupun keagamaan. Pembinaan masyarakat harus dimulai dengan mengidentifikasi aset lingkungan desa dan menemukan cara untuk membangunnya. Orientasi pembinaan masyarakat harus positif dan konstruktif (Kretzman dan McKnight 1993). Pembinaan masyarakat dengan memasukkan partisipasi masyarakat dalam pembuatan keputusan pembangunan merupakan pendekatan yang relatif baru yang menjadi elemen penting dari proses keberlanjutan (Jean 2006).

Pembinaan kemasyarakatan yang baik adalah pembinaan yang dapat menstimulus masyarakat pedesaan menjadi lebih dinamis. Keberhasilan pembinaan masyarakat dapat terlihat dari kemampuan dalam menghasilkan dan memobilisasi faktor-faktor pembangunan tidak berwujud seperti modal sosial dan pemerintahan (Jean 2006). 
Pembinaan kemasyarakatan merupakan salah satu cara efektif dalam mengembangkan modal sosial. Baiyegunhi (2013) menyimpulkan bahwa akses ke modal sosial sangat penting untuk meningkatkan kesejahteraan rumah tangga pedesaan dan pengurangan kemiskinan.

Kepemilikan modal sosial oleh rumah tangga memiliki hubungan yang kuat dengan kesejahteraan rumah tangga di perdesaan, serta positif dan signifikan terhadap pengeluaran dan pendapatan rumah tangga per kapita. Akses yang lebih baik ke modal sosial meningkatkan tingkat pengeluaran rumah tangga dan karena itu meningkatkan kesejahteraan rumah tangga. Hasil ini sesuai dengan temuan awal oleh Tiepoh dan Reimer (2004).

Banyak modal sosial yang telah terbangun selama interaksi terjadi karena alasan sosial, budaya, atau agama. Keterkaitan modal sosial dengan pembinaan kemasyarakatan di kawasan persdesaan Kabupaten Pandeglang juga sangat terkait dengan kondisi pembinaan sosial keagamaan. Asumsi di sini menunjukkan bahwa jaringan yang dibangun melalui koneksi ini terdapat ukuran kesejahteraan untuk rumah tangga yang berpartisipasi, dan karena itu mengarah pada peningkatan kesejahteraan baik secara langsung atau tidak langsung (Yusuf 2008). Oleh karena itu penting bagi pemerintah untuk memiliki pengetahuan tentang kelompok dan jaringan sosial yang ada karena hal ini akan meningkatkan efektivitas strategi saat ini yang bertujuan untuk mengurangi kemiskinan dan ketertinggal.

\section{KESIMPULAN}

Pembangunan perdesaan di Indonesia menjadi salah satu dirkursus yang paling kontemporer dalam khasanah ilmu sosial dan ekonomi. Dalam satu dekade terakhir tengah terjadi pergeseran perspektif kebijakan pembangunan yang sebelumnya sentralistik menjadi desentralistik, tak terkecuali pembangunan desa. Pembangunan yang bersifat top down telah bermetamorfosa menjadi pembangunan yang lebih buttom up dan down to earth. Masyarakat yang sebelumnya hanya menjadi objek pembangunan telah bergeser perannya menjadi subjek pembangunan. Pembangunan inklusif yang menekankan pada partisipasi masyarakat menjadi jargon utama pembangunan perdesaan.

Bergesernya bergesernya paradigma pembangunan perdesaan di Indonesia mulai terlihat sangat agresif setelah berlakunya UU 6/2014 tentang Desa. Hal tersebut terlihat dari munculnya dana transfer langsung dari APBN dan adanya dana bagi hasil dari PAD Kabupaten. Selain itu implikasi kedua berupa bertambahnya kewenangan pemerintahan desa dalam mengelola sumberdaya desa. Dalam pelaksanaan pembangunan desa, pengaruh belanja keuangan desa sangat bervariasi tergantung pada kondisi geografis, demografis, karakter budaya, dan juga sosial ekonomi masyarakat desa.

Variasi belanja keuangan desa dapat terlihat dari pengaruah belanja pembangunan infrastruktur desa sangat berkaitan dengan kondisi topografi wilayah desa. Kedua, Pengaruh belanja bidang bidang penyelenggaraan pemerintahan desa tergantung tingkat kualitas aparatur desa dan partisipasi masyarakat. Ketiga, Pengaruh belanja bidang pemberdayaan masyarakat terkait dengan komoditas dan produk unggulan desa. Keempat, Belanja desa bidang pembinaan kemasyarakatan terkait dengan kegiatan pembinaan keagamaan di desa.

\section{PENGHARGAAN}

Kami ingin menyampaikan apresiasi kepada Beasiswa Unggulan Calon Dosen Program Doktoral Kementerian Riset Teknologi dan Pendidikan Tinggi atas dukungan dalam proses perkuliahan dan penelitian. 


\section{DAFTAR PUSTAKA}

Ahmed R, Hossein M. 1990. Development Impact of Rural Structure in Bangladesh. Research Report 83. International Food Policy Research Inst itute in colaboration with Bangladesh Institute of Development Studies.

Ashok KR, Balasubramanian. 2006. Role of Infrastructure in Productivity and Diversification of Agriculture. South Asia Network of Economic Research Institutes (SANEI) Pakistan Institute of Development Economics, Islamabad, Pakistan.

Aschauer DA. 1989. Public investment and productivity growth in the group of seven. Economic Perspectives. 13(5):17-25.

Ayoola GB. (2001), Essays on The Agricultural Economy 1: A Book of Readings on Agricultural Development Policy and Administration in Nigeria: Ibadan: TMA Publishers. Food and Agricultural Organisation (FAO), (2004) The Ethics of Sustainable Agricultural Intensification

Baiyegunhi LJS. 2013. Rural households' social capital and welfare: A case study of Msinga, KwaZulu-Natal, South Africa. Journal of Agriculture and Rural Development in the Tropics and Subtropics, Vol. 114 No. 2 (2013) 123-132

Beckley T, Nadeau S, Wall E, Martz D. 2002. Multiple Capacities, Multiple Outcomes: Delving Deeper Into the Meaning of Community Capacity. Submitted to the Journal of Rural Studies.

Bjornestad L. 2009. Fiscal Decentralization, Fiscal Incentives, and Pro-Poor Outcomes: Evidence from Vietnam. ADB Economics Working Paper Series No. 168, Asian Development Bank. Metro Manila.

Creightney C. 1993. Transport and economic performance: a survey of developing countries, Report, World Bank.

Ekong EE. 2003. Introduction to Rural Sociology: An Introduction and Analysis of Rural Nigeria, Uyo, Nigeria: Dave Educational Publishers

Fan, Kang C. 2004. Is Small Beautiful ? Farm Size, Productivity, and Poverty in Asian Agriculture. Agric Econ Journal, 32: 135-146

Fischer M, Scolten HJ, David. 1996. Spatial Analysis Perpectives on GIS. GISDATA 4. London: Taylor \& Francis.

Flora J. 2001. Community, Organization and Government: Community Capacity and the New Rural Economy. Paper presented at the Canadian Rural Revitalization Foundation Conference. October, 2001. Muenster, Saskatchewan.

Fotheringham AS. 2002. Geographically Weighted Regression The Analysis of Spatially Varying Relationships. US. John Wiley \& Sones

Frank F, Smith A. 1999. The Community Development Handbook: A Tool to Build Community capacity. Canada: Human Resources Development Canada.

Gieske H, van Buuren A, Bekkers V. 2016. Conceptualizing Public Innovative Capacity: A Framework for Assessment. The Innovation Journal: The Public Sector Innovation Journal, 21(1): 1-27.

Howe J, Mc Mahon E, Propst L. 1997. Balancing Nature and Commerce in Gateaway Communities. Island Press:Waashington D.C-Covelo California.

Jean S. 2006. Traditions of sustainability in tourism studies. Annals of Tourism Research, 33(4), 1121-1140

Juanda B, Wibowo K, Millich L. 2013. Studi Efektivitas dan Dampak Kursus Keuangan Daerah (KKD) dan Kursus Keuangan Daerah Khusus (KKDK).Jakarta: Direktorat Jenderal Perimbangan Keuangan Republik Indonesia.

Kogoya T, Olfie B, Laoh OE. 2015. Partisipasi Masyarakat terhadap Pembangunan Infrastruktur Jalan Desa di Kabupaten Lanny Jaya-Papua. Jurnal Berkala Ilmiah Efisiensi. 15 (2):1-14.

Kretzmann, John P, McKnight JL. 1993. Building Communities from the Inside Out: A Path Toward Finding and Mobilizing a Community's Assets. Chicago, IL: ACTA Publications.

Kwon E. 2001. Infrastructure, growth, and poverty reduction in Indonesia: A cross-sectional analysis. Mimei. Manila: Asian Development Bank

Lall S, Shalizi Z, Deichmann U. 2001. Agglomeration Economies And Productivity In Indian Industry. The World Bank, Washington DC, 20433

Lestari ER. 2015. Implementasi Kebijakan Otonomi Desa di Desa Pilanjau Kecamatan Sambaliung Kabupaten Berau. eJournal Administrasi Negara, 3 (2): 466-479. 
Malmberg S, Hawton K, Simkin S. 1997. A Study of suicide in farmer in England and Wales. Journal of Psychosomatic Research, 43 (1), 107-111.

Mischen PA, Sinclair TAP. 2017. Small is Beautiful: Knowledge Management and Budget Reform in a Rural County. The Innovation Journal: The Public Sector Innovation Journal, Volume 22(1), 2017, article 2.

Moore J. 2005. Policy, priorities and action: A case study of the University of British Columbia's engagement with sustainability. Higher Education Policy Journal. Vol. 18: 179-197.

Narayan D. 2002. Empowerment and Poverty Reduction: A Sourcebook. Washington, DC: The World Bank.

Oates WE. 1999. An Essay on Fiscal Federalism. Journal of Economic Literature, 27(5): 1120-1149

Pade SP. 2015. Pentingnya Kualitas Aparat Pemerintah Desa dalam Pembangunan di Desa Lantung Kecamatan Wori Kabupaten Minahasa Utara. Jurnal Politico. 2(6):1-12.

Parvayi S. 2011. Possible consequences of targeted subsidies plan. Development Strategy Journal, 27, 173-192

Pranoto S. 2005. Pembangunan Perdesaan Berkelanjutan Melalui Model Pengembangan Agropolitan. Tesis Sekolah Pascasarjana IPB. Bogor

Pribadi DO. 2005. Pembangunan Kawasan Agropolitan Melalui Pengembangan Kota-Kota Kecil Menengah, Peningkatan Efisiensi Pasar Perdesaan dan Penguatan Akses Masyarakat terhadap Lahan. Tesis Sekolah Pascasarjana IPB. Bogor

Rahimi FAF. 2015. Towards community empowerment for poverty reduction in rural Afghanistan. Journal of Asia Pacific Studies. Volume 34, 34-42

Ranjbar H, Fotros MH, Kabiryan M. 2014. the effect of targeted subsidies on consumer welfare equivalent change in Iran. Iranian Journal of Applied Economic Research, 9, 133-149.

Reimer B. 2006. The rural context of community development in Canada. Journal of Rural and Community Development. Volume 1, 155-175.

Rietveld R, Nijkamp R. 1992. Transport and Regional Development. Faculteit der Economische Wetenschappen en Econometrie. Research-Memorandum 1992-50 December 1992

Shahmoradi A, Haghihi I, Zahedi R.. 2011. the effects of energy prices and cash subsidy in Iran. Research and Economic Policy Journal, 57, 5-30.

Strzelecka M. 2015. The prospects for empowerment through local governance for tourism-the LEADER approach. The Journal of Rural and Community Development, 10(3), 78-97.

Tiepoh MGN, Reimer B. 2004. Social capi-tal, information flows and income creation in Rural Canada: A Cross Community Analysis. Journal of Social Economics, 33, 427-466.

Valentin EK. 2001. SWOT analysis from a resource-based view. Journal of Marketing Theory and Practice. 9(2): 54-68.

Vennesland B. 2003. Rural economic development and its influence on forest policy in Norway. In: Solberg, B. (Ed.). Scandinavian Forest Economics Journal, No. 37, pp. 290- 297

Warsono H, Ruksamin. 2014. The Obstacles of Implementation of Village Allocation Fund Program in the North Konawe Southeast Sulawesi. Journal of Management and Sustainability, Vol. 4, No. 3; 2014

Yusuf SA. 2008. Social capital and household welfare in Kwara State, Nigeria. Journal of Human Ecology, 23 (3), 219-229. 